\title{
Etograma do Garcará (Caracara Plancus, Miller, 1777) (Aves, Falconidae), em cativeiro
}

\author{
HELON SIMÕES OLIVEIRA ${ }^{1 *}$, DAUANA RITA DE ALCÂNTARA SOUZA ${ }^{1}$, \\ MARIA NEI DA SILVA ${ }^{1}$
}

\begin{abstract}
Neste trabalho foi elaborado um etograma com base em observações comportamentais de seis carcarás (Caracara plancus), sendo quatro fêmeas e dois machos em cativeiro. As observações ocorreram no Parque dos Falcões localizado na Serra de Itabaiana, Rio das Pedras, SE. A identificação dos comportamentos foi realizada através do método ad libitum, com 12 horas diárias de observação $(5$ às $17 \mathrm{~h}$ ) totalizando 96 horas de esforço amostral. Posteriormente foram realizadas observações por meio do método animal-focal, para o registro das frequências e duração dos comportamentos, que resultou em um total de 70 horas de esforço amostral. Durante a pesquisa foram observados e descritos 25 estados comportamentais agrupados em cinco categorias. Receberam uma descrição detalhada com esquematização, sendo os comportamentos de descanso os mais expressivos.
\end{abstract}

Palavras-chave: Caracara plancus; carcará; cativeiro; comportamentos; etograma.

In this paper an ethogram was produced based on behavioral observations of six southern "caracaras" (Caracara plancus), being four females and two males in captivity. Observations occurred in the Parque dos Falcões, located in Serra de Itabaiana, Rio das Pedras, SE, Brazil. The identification of behaviors was performed using the method ad-libitum, with 12 hours of observation everyday (5h to $17 \mathrm{~h}$ ), totaling 96 hours of sampling effort. Subsequently observations were made by the method animal-focal, to record the frequency and duration of behaviors, resulting in a total sampling effort of 70 hours. During the research were observed and described 25 behavioral states grouped in five categories, which received detailed description with schematization, being the rest behaviors the most significant ones.

Keywords: Behaviors; Caracara Plancus; captivity; ethogram; southern caracara.

\section{Introdução}

Da família Falconidae, o Caracara plancus (Miller, 1777) é uma das espécies de Falconiformes com dieta variada, acompanhada de diversas táticas alimentares (Sazima, 2007). O Carcará é uma das aves de rapina mais comuns no Brasil, medindo cerca de $56 \mathrm{~cm}$ da cabeça a cauda e $123 \mathrm{~cm}$ de envergadura (Sick, 2001). Por ser um carnívoro oportunista, provavelmente é a ave de rapina mais bem-sucedida. Alimenta-se de invertebrados, vertebrados e também de cadáveres e lixo urbano. Segundo Souto (2008), quando em condições favoráveis e com abundância de alimento, o Carcará pode compartilhar espaço de forrageio com o Urubude-cabeça-preta (Coragyps atratus, Bechstein, 1793), e muitas vezes são vistos realizando catação entre si.

De acordo com a União Internacional para a Conservação da Natureza e dos Recursos Naturais
(IUCN), a distribuição do Carcará ocorre desde a região Norte do Brasil até as ilhas Malvinas, sendo uma ave comum na região da Serra de Itabaiana, no estado de Sergipe (Carvalho \& Vilar, 2005). A seleção dos habitats é baseada em diversos fatores, como variedade de vegetação, marcadores de produtividade e competições inter e intraespecíficas (Alcock, 2011). Se um animal é retirado do seu ambiente natural há probabilidade de causar estresse no mesmo (Lima, Ludke, Neto, Pimentel \& Valadares, 2011), porém esse estado de perturbação é inversamente proporcional à capacidade dos indivíduos de se adaptarem ao meio (Broom, 1986 citado por Lima et al., 2011).

As pesquisas etológicas também visam a colaborar no desenvolvimento de ambientes projetados que atendam as necessidades dos animais. Um ambiente que mantenha os animais em cativeiro deve levar em consideração as características de

\footnotetext{
Departamento de Biologia - Universidade Tiradentes.

* Autor correspondente: helonbio@hotmail.com
} 
cada espécie de indivíduos que ali residam, proporcionando assim um ambiente adaptável e cômodo (Souto, 2005). Etogramas e repertórios comportamentais são ferramentas básicas para uma melhor compreensão da biologia de um animal em condições de cativeiro ou em vida livre (Alcock, 1997). Seu objetivo é listar os comportamentos de determinadas espécies, e por meio disso reconhecer e estudar os comportamentos do animal e correlacioná-los com diversos fatores ambientais (Souto, 2005).

Vários autores (Dove \& Banks, 1999; Franzo et al., 2009; Galetti \& Guimarães Jr, 2004; Marini et al., 2007; Martinelli, 2010; Ribeiro et al., 2008; Tomazzoni, Pedó \& Hartz, 2005; Travaini, Donázar, Ceballos \& Hiraldo, 2001) relatam aspectos biológicos do Caracara plancus - taxonomia, hábitos alimentares, nidificação, morfofisiologia e ecologia. Bertazzoni, Dall'acqua, Luiz, Vilas Boas e Albuquerque (2005) descrevem aspectos comportamentais da ave em vida livre, e Souto (2008) descreve duas condutas do Carcará. Entretanto, não há referências quanto ao seu comportamento em cativeiro.

Em cativeiro, o animal altera seu comportamento a fim de adaptar-se ao novo meio (Albuquerque, Silveira e Oliveira, 2009). O estudo de uma espécie confinada, que apresenta comportamentos naturais e alterados, visa auxiliar o manejo adequado para o bem-estar desse indivíduo (Albuquerque et al., 2009). Devido à carência de estudos comportamentais a respeito da espécie e com o intuito de ampliar os conhecimentos sobre o Caracara plancus, é necessário um estudo comportamental da ave em cativeiro. Assim, o objetivo deste trabalho foi a confecção do etograma qualitativo e quantitativo do Caracara plancus em cativeiro, que complementa as informações disponíveis sobre a biologia da espécie.

\section{Material e Método}

O estudo foi realizado entre os meses de junho a outubro de 2013 no Parque dos Falcões (1044.836'S; 37²2.713'O), localizado na Serra de Itabaiana, no povoado Rio das Pedras - SE.

O Parque Nacional Serra de Itabaiana (PNSI) (1040'52'S e 37²5'15”W, 180-660 m, 7966 ha) abrange os municípios de Areia Branca, Laranjeiras, Itaporanga d'Ajuda e Campo do Brito; o clima local é quente e úmido, com chuvas de outono-inverno (1200 $\mathrm{mm}$ a $1300 \mathrm{~mm}$ /ano), e as temperaturas médias mensais oscilam entre $17^{\circ} \mathrm{C}$ e $23^{\circ} \mathrm{C}$ (A. C. C. Bezerra, M. de F. de A. Bezerra, Nunes, Lado \& Cavalcanti, 2008).
O Parque dos Falcões foi fundado no ano 2000, possui extensão de 7 ha e hoje abriga mais de 300 aves, sendo a maioria de rapina e regulamentadas pelo IBAMA. Muitas dessas foram resgatadas do tráfico de animais, vítimas de maus-tratos ou nascidas em cativeiro. O Parque cuida das aves doentes e/ou feridas, faz o manejo de reprodução, treinamento, reabilitação e quando possível realiza a soltura desses animais.

\section{Animais e Recinto}

Os carcarás foram distribuídos em seis recintos (Figura 1), com um indivíduo em cada um deles. Os recintos são estruturas de alvenaria com dimensões 2 m x 2 m x 2,5 m e cobertos com telha de amianto; possuíam três poleiros de madeira, três janelas e uma porta nos fundos, todas protegidas com tela de aço. Uma banheira de água para banho foi colocada em cada recinto duas vezes por semana. Os indivíduos foram alimentados em dias alternados com carne de boi (Bos taurus), pintinho (Gallus gallus domesticus) e codornas (Nothura boraquira). As aves foram denominadas de C1 a C6, sendo quatro fêmeas e dois machos adultos.

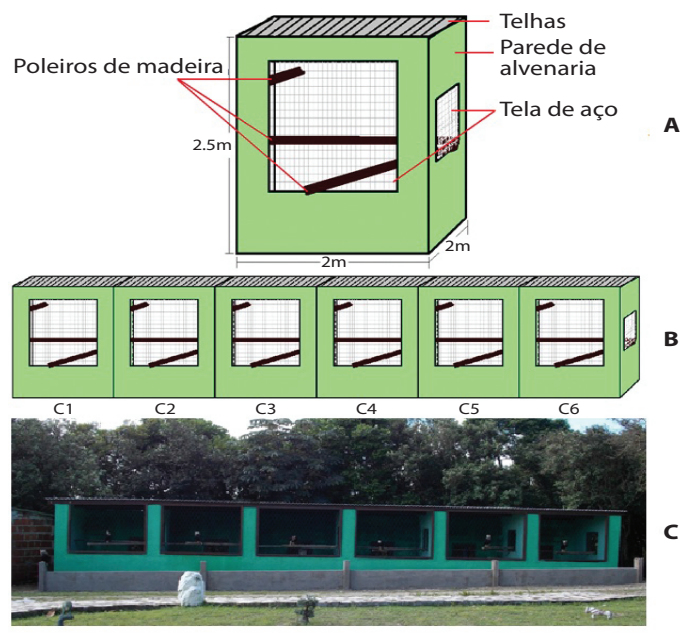

Figura 1. (A) detalhe do recinto; (B) disposição dos recintos; (C) foto do recinto. Desenho: H.S. Oliveira; Foto: H.S. Oliveira.

\section{Coleta de Dados}

A coleta de dados foi realizada pela técnica de amostragem ad libitum (Altmann, 1974) - técnica na qual o observador identifica e descreve todos os comportamentos (sem repetições) do animal -, nos meses de junho e julho, em 8 turnos com duração de $12 \mathrm{~h}$ 
cada. Por meio da técnica de amostragem AnimalFocal (Altmann, 1974) os dados foram coletados em 10 turnos, com duração de 7 h cada um e fracionados em 14 sessões diárias, durante os meses de agosto e setembro. Cada sessão focal totalizava 30 minutos divididos em observações individuais de 5 minutos para cada animal e 10 minutos de intervalo entre as sessões. Todos os comportamentos observados foram registrados em planilhas pré-estabelecidas. Após as observações quantitativas, os dados coletados foram organizados em tabelas, proporcionando a visualização da frequência e da duração total de cada comportamento. Mesmo que a observação de comportamentos aprendidos - comportamentos comandados pelos tratadores - não seja o alvo desta pesquisa, foram incluídos nas observações quantitativas para se averiguar a frequência com que ocorrem.

As observações ocorreram a uma distância de $25 \mathrm{~m}$ dos recintos. Foi utilizado um binóculo Expanse de 10 x $50 \mathrm{~mm}$ e duas câmeras (Nikon Coolpix L810 e Sony Cyber-shot DCS-W570) para a realização das filmagens e fotografias dos comportamentos a serem analisados.

Os registros fotográficos e de vídeos, assim como a descrição detalhada de cada ato comportamental, proporcionaram a elaboração de um catálogo ilustrado dos atos, confeccionado por um dos autores do trabalho.

\section{Resultados}

Foram realizados 8 dias de observação por meio da técnica de amostragem ad libitum, totalizando $96 \mathrm{~h}$ de esforço total e esforço amostral. Durante a pesquisa foram observados, identificados e descritos 25 comportamentos agrupados em cinco categorias comportamentais (Tabela 1).

Tabela 1. Comportamentos observados, agrupados em suas respectivas categorias.

\begin{tabular}{cl}
\hline Categoria & \multicolumn{1}{c}{ Comportamentos } \\
\hline Manutenção & Limpar penas; limpar bico; limpar \\
& pata; espirrar; banho; sacudir \\
& plumagem; coçar. \\
Descanso & Posição neutra; bocejar; dormir; \\
& imitar mastigação; espreguiçar. \\
Locomoção & Correr; andar; saltar; voar. \\
Alimentação & Comer; ciscar; defecar; regurgitar; \\
& beber água. \\
Social & Vocalizar I; vocalizar II; vocalizar III; \\
& ataque físico. \\
\hline
\end{tabular}

\section{Manutenção}

1. Limpar penas: A ave utiliza o bico para a limpeza das penas ao debicar ou ao alisar as mesmas. Esse ato pode ser executado de diversas maneiras, tanto com a cabeça voltada para o dorso como com o bico próximo ao ventre. Na região do peito, do pescoço e da nuca, a ave puxa ou debica rapidamente as pequenas penas e balança a cabeça lateralmente. Na cauda, a ave mantém a cabeça voltada para as costas e deixa as retrizes erguidas e entreabertas em forma de leque. O Carcará inicia o alisamento da pena puxando-a da base até a extremidade, depois o mesmo processo é repetido nas asas. A limpeza das polainas das pernas pode dar-se com uma das patas erguidas e com rápidas debicadas (Figura 2A).

2. Limpar o bico: A ave raspa, alternadamente, as laterais do bico contra o poleiro ou a tela do recinto (Figura 2B).

3. Limpar patas e garras: A ave ergue a pata na altura do peito e com os dedos entreabertos retira restos de carne ou resíduos do solo com o auxílio do bico (Figura 2C).

4. Espirrar: Em postura neutra a ave espirra com leves sacudidas de cabeça, reproduz juntamente com esse movimento um som semelhante a "tshhh", voltando à posição anterior (Figura 2D).

5. Banho: Com as patas imersas na água e as penas eriçadas, a ave mergulha cabeça, pescoço e peito. Sacode as penas e a cauda desde o mergulho até a submersão na água, erguendo o bico e fazendo a água espalhar pelo dorso, e depois bate as asas. Após os mergulhos, a ave costuma sacudir-se por completo (Figura 2E).

6. Sacudir plumagem: A ave eriça as penas da cabeça, pescoço, peito, ventre e dorso e as sacode em semicírculos curtos e rápidos. Esse movimento pode ocorrer somente com as penas da coroa, occipício, nuca e garganta, ou somente na cauda com as retrizes entreabertas e lançadas lateralmente (Figura 2F).

7. Coçar: A ave ergue uma das patas com os dedos entreabertos até a altura do peito e mantém a 
cabeça voltada para o lado, coça a região do dorso da cabeça, região perioftálmica, bico, pescoço ou ouvido. O movimento da pata é bastante rápido e as penas dessas regiões mantêm-se eriçadas. Com o bico a ave debica a pele dos dedos e pernas a fim de coçá-los; por fim ergue o corpo e volta pousando a pata no poleiro (Figura 2G).
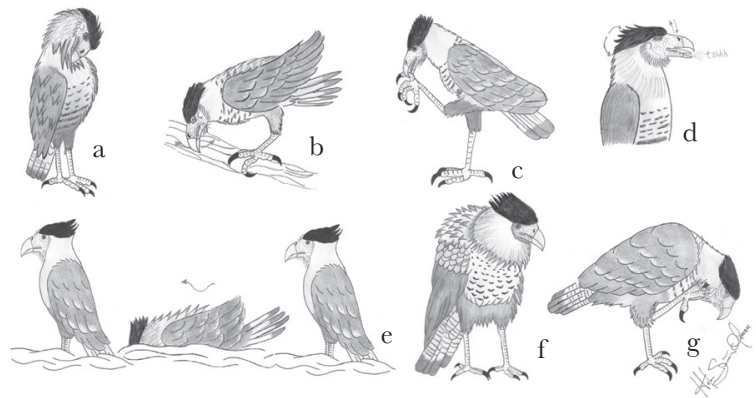

Figura 2. Ilustrações esquemáticas dos comportamentos da categoria Manutenção: (A) Limpar penas; (B) Limpar bico; (C) Limpar pata; (D) Espirrar; (E) Banho; (F) Sacudir plumagem; (G) Se coçar. Desenho: H. S. Oliveira.

\section{Descanso}

1. Posição neutra: A ave mantém as pernas paradas e levemente afastadas; a cauda apresenta-se caída e as asas junto ao corpo. As penas não ficam eriçadas, o pescoço permanece na posição normal - isso é, nem encolhido nem distendido - e o bico fechado. Por vezes, em postura neutra, a ave alterna o recolhimento de uma das patas próxima ao peito escondida sob as penas (Figura 3A).

2. Bocejar: Em postura neutra, a ave abre e fecha o bico ao mesmo tempo em que eleva a língua e distende o pescoço para cima e para trás em um movimento lento (Figura 3B).

3. Dormir: Em posição neutra com uma das patas recolhida sob as penas do ventre, a ave volta a cabeça para o dorso e esconde o bico e cera na plumagem eriçada do mesmo (Figura 3G).

4. Imitar mastigação: A ave abre e fecha o bico repetidamente com velocidade variável.
5. Espreguiçar: A partir da posição neutra, a ave ergue o corpo, distende o pescoço para frente e estica a pata e a asa para a lateral voltada um pouco para baixo; o corpo é levemente inclinado para o lado oposto a fim de manter o equilíbrio. A cauda é aberta em forma de leque. É bastante visível o esforço que a ave faz para distender a musculatura de todo o corpo, incluindo a dos dedos (Figura 3D).
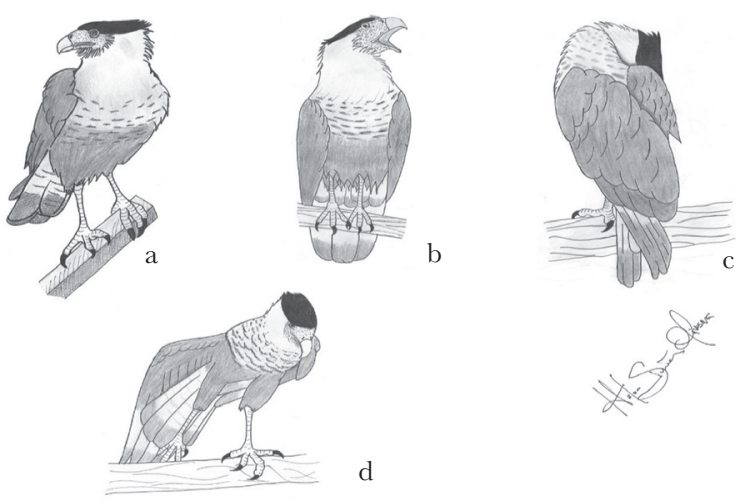

Figura 3. Ilustrações esquemáticas dos comportamentos da categoria Descanso: (A) Posição neutra; (B) Bocejar; (C) Dormir; (D) Espreguiçar. Desenho: H. S. Oliveira.

Locomoção

1. Correr: A ave corre batendo as asas com o pescoço distendido e o corpo inclinado para frente (Figura 4A).

2. Andar: Com passos ritmados, a ave projeta a cabeça para frente seguida do corpo. Também houve registros de passos com deslocamento lateral (Figura 4B).

3. Saltar: Sobre as duas patas, a ave fixa o olhar no local do pouso, inclina-se para frente para gerar impulso e salta com o auxílio do bater de asas de uma a duas vezes. No entanto, para saltar do poleiro para o chão, a ave lança-se do poleiro com as asas abertas (Figura 4C).

4. Voar: Sobre as duas patas, a ave fixa o olhar no próximo local de pouso, inclina-se para frente para gerar impulso, bate as asas para levantar voo e erguer-se a um plano mais alto (Figura 4D). 


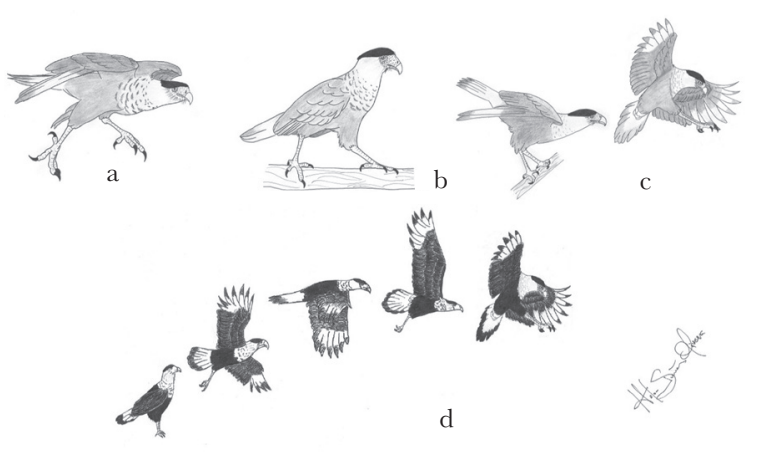

Figura 4. Ilustrações esquemáticas dos comportamentos da categoria Locomoção: (A) Correr; (B) Andar; (C) Saltar; (D) Voar. Desenho: H. S. Oliveira.

\section{Alimentação}

1. Comer: A ave prende firme e fortemente a carne no chão com as garras de uma das patas, com o bico arranca pedaços menores de alimento, os engole por inteiro e quando encontra ossos quebra-os se forem muito grandes. Após arrancar cada pedaço de carne, ergue o pescoço para deglutir e retorna a baixar a cabeça para arrancar outro pedaço. A pata que fixa a carne no chão pode ser alternada durante a alimentação. Muito vigilante, a ave para de alimentar-se varias vezes, ergue a cabeça e a movimenta de um lado para o outro a fim de observar ao seu redor (Figura 5A).

2. Ciscar: A ave caminha de cabeça baixa a procura de invertebrados e pedras pequenas no solo. Por vezes ela raspa a superfície do lugar com as garras e dá um ou dois passos para trás a fim de observar alguma possível presa que estava submersa (Figura 5B).

3. Defecar: Sobre as duas patas, a ave levanta levemente a cauda e eriça as penas do crisso, rapidamente elimina as fezes e retorna para a posição anterior. Permanece praticamente imóvel durante todo o comportamento (Figura 5G).

4. Regurgitar: Em posição neutra a ave abre o bico, distende o pescoço para frente e regurgita as partes não digeríveis dos alimentos, como penas, bico, cascos e carapaças de insetos. Para soltar os pedaços que ficam presos em sua garganta, a ave balança a cabeça até que se desprendam.

5. Beber água: Com o corpo em posição neutra a ave mergulha o bico na água e rapidamente ergue a cabeça para deglutir a água coletada (Figura 5D).
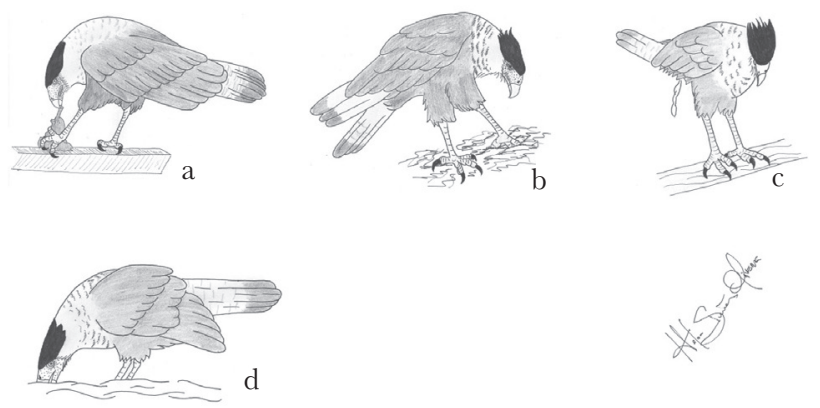

Figura 5. Ilustrações esquemáticas dos comportamentos da categoria Alimentação: (A) Comer; (B) Ciscar; (C) Defecar; (D) Beber água. Desenho: H.S. Oliveira.

Social

1. Vocalizar I: A ave mantém a postura ereta e permanece em postura de alerta. A cabeça permanece imóvel e o bico abre para emitir o som. O som consiste em repetidos "crá crá crá", sem intervalos entre eles (Figura 6A).

2. Vocalizar II: A ave mantém seu corpo em posição neutra e a cabeça faz leves movimentos de $90^{\circ}$ para cima, juntamente com o som emitido. O som consiste em repetidos "crá", com breves intervalos entre um movimento e outro (Figura $6 B)$.

3. Vocalizar III: A ave mantém seu corpo em posição neutra e a cabeça faz bruscos movimentos de $180^{\circ}$ em direção ao dorso, juntamente com o som emitido. A vocalização III tem como antecessor a vocalização I. É realizada a vocalização I e em seguida a ave realiza os movimentos de cabeça junto de um som que consiste em longos "cráááá" (Figura 6C).

4. Ataque fisico: A ave corre de encontro a outro indivíduo, salta e com as garras levantadas na altura do abdômen executa o ataque juntamente com vocalizações (Figura 6D). 


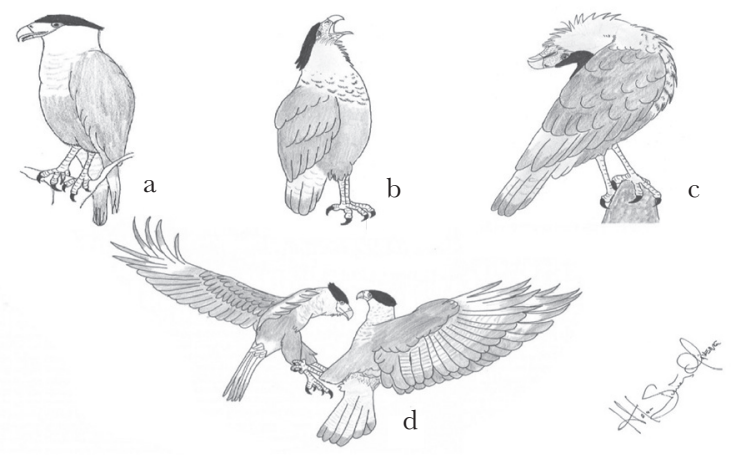

Figura 6. Ilustrações esquemáticas dos comportamentos da categoria Social: (A) Vocalizar I; (B) Vocalizar II; (C) Vocalizar III; (D) Ataque Físico. Desenho: H.S. Oliveira.

Durante as observações preliminares, o reconhecimento de comportamentos diferentes se estabilizou no quarto dia, como é possível visualizar na Figura 7. É também importante elucidar que determinados comportamentos, como o de corte, não foram observados devido ao confinamento em cativeiro, e por esta pesquisa não ter sido realizada na época de reprodução dos animais.

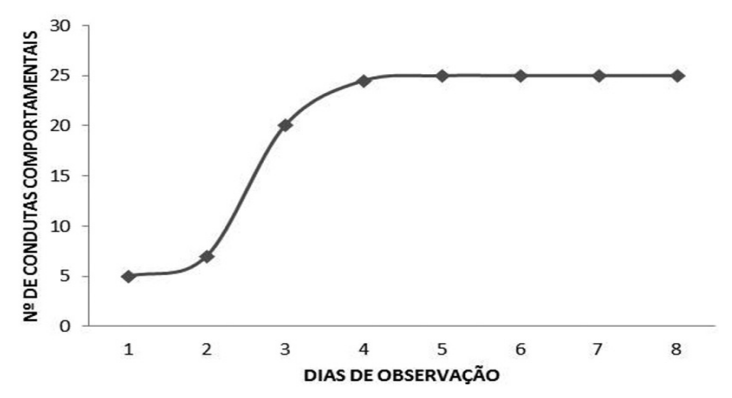

Figura 7. Identificação de novos comportamentos de Caracara plancus ( $\mathrm{n}=6$ aves) em relação ao número de dias de observação $(n=96 \mathrm{~h})$, no Parque dos Falcões, Itabaiana - SE.

Pela técnica de amostragem Animal-Focal, foram obtidos 5316 registros em $70 \mathrm{~h}$ de esforço amostral, realizados em 10 dias de observação, totalizando $120 \mathrm{~h}$ de esforço total (Tabela 2).

Tabela 2. Ocorrência, frequência absoluta e duração total dos comportamentos de seis Caracara plancus observados em cativeiro.

\begin{tabular}{|c|c|c|c|c|c|c|c|c|c|c|c|c|}
\hline \multicolumn{13}{|c|}{ Dias de amostragem } \\
\hline Comportamentos & 1 & 2 & 3 & 4 & 5 & 6 & 7 & 8 & 9 & 10 & Total & Duração (h) \\
\hline Posição neutra & 206 & 197 & 198 & 236 & 173 & 214 & 234 & 231 & 241 & 246 & 2176 & 40:29:49 \\
\hline Limpar penas & 58 & 106 & 84 & 99 & 81 & 88 & 87 & 92 & 101 & 67 & 863 & $15: 24: 19$ \\
\hline Ciscar & 15 & 13 & 20 & 27 & 12 & 27 & 21 & 15 & 26 & 24 & 200 & 03:38:41 \\
\hline Comer & 20 & 13 & 3 & 0 & 7 & 6 & 12 & 5 & 0 & 8 & 74 & 03:20:18 \\
\hline Saltar & 65 & 47 & 72 & 91 & 72 & 83 & 93 & 54 & 71 & 115 & 763 & 01:32:05 \\
\hline Dormir & 2 & 3 & 2 & 4 & 4 & 7 & 5 & 2 & 3 & 2 & 34 & 01:28:44 \\
\hline Andar & 48 & 43 & 34 & 33 & 32 & 60 & 47 & 45 & 30 & 30 & 402 & $01: 14: 21$ \\
\hline Vocalizar & 15 & 24 & 7 & 9 & 10 & 1 & 12 & 3 & 5 & 9 & 95 & $00: 47: 43$ \\
\hline Coçar & 8 & 17 & 10 & 22 & 20 & 7 & 20 & 18 & 19 & 12 & 153 & $00: 19: 29$ \\
\hline Limpar bico & 12 & 13 & 8 & 8 & 8 & 5 & 10 & 7 & 15 & 1 & 87 & $00: 18: 06$ \\
\hline $\mathrm{CA}^{*}$ & 1 & 1 & 2 & 1 & 0 & 0 & 0 & 1 & 2 & 3 & 11 & $00: 13: 55$ \\
\hline Espreguiçar & 8 & 9 & 2 & 5 & 5 & 3 & 5 & 13 & 3 & 4 & 57 & $00: 13: 51$ \\
\hline Voou & 6 & 16 & 0 & 3 & 10 & 15 & 10 & 3 & 6 & 2 & 71 & $00: 12: 46$ \\
\hline Banho & 0 & 0 & 0 & 0 & 6 & 0 & 0 & 0 & 0 & 0 & 6 & $00: 12: 33$ \\
\hline Sacudir Plumagem & 3 & 12 & 10 & 3 & 9 & 4 & 6 & 0 & 8 & 9 & 64 & 00:06:39 \\
\hline Bocejo & 3 & 7 & 3 & 10 & 6 & 4 & 4 & 3 & 6 & 7 & 53 & $00: 05: 51$ \\
\hline Limpar Pata & 4 & 4 & 1 & 1 & 2 & 7 & 2 & 1 & 4 & 2 & 28 & $00: 05: 17$ \\
\hline Sacudir rabo & 7 & 2 & 5 & 2 & 2 & 15 & 3 & 6 & 15 & 7 & 64 & 00:05:10 \\
\hline Defecar & 10 & 6 & 5 & 6 & 5 & 2 & 3 & 7 & 12 & 2 & 58 & $00: 03: 54$ \\
\hline Atacar & 1 & 4 & 2 & 0 & 1 & 2 & 0 & 0 & 0 & 0 & 10 & $00: 02: 53$ \\
\hline Imitar mastigação & 0 & 1 & 2 & 0 & 2 & 0 & 0 & 0 & 11 & 4 & 20 & $00: 01: 16$ \\
\hline Gorrer & 1 & 2 & 0 & 0 & 1 & 0 & 1 & 3 & 0 & 3 & 11 & 00:01:00 \\
\hline Regurgitar & 0 & 3 & 1 & 0 & 0 & 0 & 0 & 0 & 0 & 0 & 4 & $00: 00: 43$ \\
\hline Sacudir cabeça & 0 & 0 & 2 & 2 & 0 & 0 & 1 & 0 & 1 & 0 & 6 & 00:00:26 \\
\hline Espirrar & 0 & 0 & 0 & 1 & 1 & 1 & 3 & 0 & 0 & 0 & 6 & $00: 00: 11$ \\
\hline Total de registros & & & & & & & & & & & 5316 & 70:00:00 \\
\hline
\end{tabular}

*CA: comportamentos aprendidos. 
Os resultados agrupados nas categorias comportamentais possibilitou a visualização em porcentagem da frequência e duração total por categoria.

\section{Discussão}

As categorias que obtiveram maior frequência foram "descanso", seguida por "locomoção" e "manutenção" (Figura 8). Com relação à duração (Figura 9), as categorias "alimentação" e "social" se mantiveram proporcionais à sua frequência. No entanto, "locomoção" e "descanso" tiveram valores de duração diferentes da sua frequência.

Os valores das frequências absolutas e durações dos comportamentos aprendidos foram baixos, pois ocorriam ocasionalmente mediante os comandos emitidos pelos tratadores durante demonstrações dirigidas aos turistas.

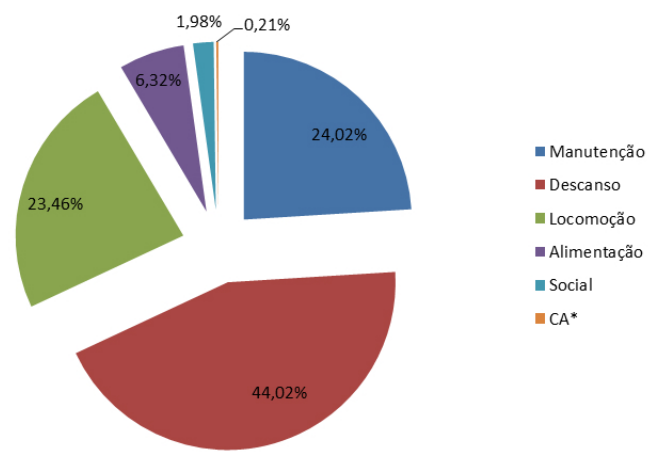

Figura 8. Frequência em porcentagem por categoria comportamental de seis C. plancus em cativeiro.

*CA: Comportamentos aprendidos.

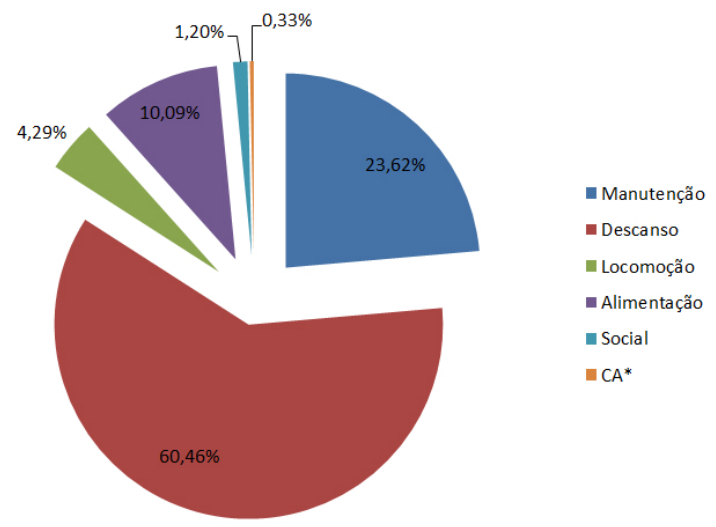

Figura 9. Duração em porcentagem por categoria comportamental 1 de seis $C$. plancus em cativeiro.

*CA: Comportamentos aprendidos.
Durante as observações, os animais tiveram um pico de atividade no período entre as $08 \mathrm{~h}$ e as $10 \mathrm{~h}$ e momentos de maior quietude entre as $13 \mathrm{~h}$ e as $15 \mathrm{~h}$ (Figura 10).

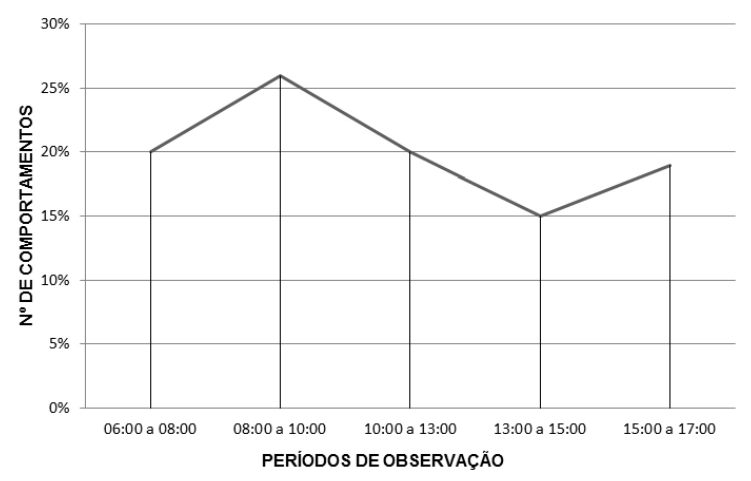

Figura 10. Média de atividades ao longo do dia dos seis Caracara plancus em cativeiro.

Os comportamentos do Caracara plancus foram comparados com outras espécies de famílias distintas com o intuito de avaliar esses comportamentos no nível da classe das Aves.

Em seu trabalho com a Garça-BrancaGrande (Casmerodius albus, Linnaeus, 1758) em vida livre, Henrique e Piratelli (2008) mostram que essas garças passaram $45 \%$ do tempo de observação realizando comportamentos de manutenção, 18\% locomovendo-se, 27\% alimentando-se e 10\% realizando comportamentos sociais e de vigilância, onde as condutas de limpeza apresentaram maior duração de execução.

Nos dados extraídos de Prestes (2000), a espécie Amazona pretrei (Temminck, 1830), em cativeiro, demonstra as maiores taxas de ocorrência para a categoria "manutenção" (2,03x/min), sobressaindo-se novamente nos comportamentos de "descanso" com 1,37x/min e Limpeza com 0,36x/min.

Esses dados condizem com os dados de $C$. plancus, que também tiveram seus maiores valores nas categorias de Manutenção e Descanso nos comportamentos de posição neutra (descanso) e limpeza.

Apesar de não fornecer dados quantitativos para o Ramphastos toco (Vigors, 1825) em cativeiro e para o Molothrus bonariensis (Gmelin, 1789) em vida livre, Mikich (1991) e Porto e Piratelli (2005), respectivamente, demonstraram que todos os comportamentos obtidos com $C$. plancus também são visíveis em seus animais de estudo, ressaltando a presença da regurgitação em $R$. toco e $A$. pretrei. 


\section{Conclusão}

De acordo com a curva de surgimento de novos comportamentos, não se observaria novas condutas mesmo com a continuação das observações até que os espécimes entrassem no período reprodutivo ou fossem remanejados. Os resultados obtidos com este estudo mostram uma parte significativa do repertório comportamental de Caracara plancus em cativeiro, o que pode não só aprimorar o conhecimento sobre a espécie, mas também auxiliar o seu manejo em cativeiro.

No estudo realizado por Bertazzoni et al. (2005), nota-se maior frequência de atividades nas categorias "descanso" e "deslocamento" em ambas as áreas de observação. Ao comparar os dados obtidos neste estudo, observa-se semelhanças nas categorias "locomoção" e "descanso", além de ser possível notar que os animais podem exibir muitas repetições de alguns comportamentos de curta duração e maior duração em outros, como os da categoria "descanso". As categorias "alimentação" e "social" tiveram seus valores baixos devido ao ambiente de cativeiro, com pouco contato entre os animais e com alimentação regrada.

Este é o primeiro estudo que analisa o comportamento dessa espécie em cativeiro. Devido a esse ambiente, os padrões comportamentais podem ter sofrido algumas alterações em suas frequências e durações em relação aos indivíduos de vida livre. Dessa forma, são necessários estudos com espécimes não cativas para que se possa transpor os resultados para a espécie como um todo.

\section{Referências}

Albuquerque, M. C. F. De, Silveira, B. M. Da R. \& Oliveira, M. A. (2009). Análise comportamental do pelicano-branco (Pelecanus onocrotalus, Linnaeus, 1758) em cativeiro no parque estadual dois irmãos. In IX Fornada de Ensino, Pesquisa e Extensão - JEPEX, Universidade Federal Rural de Pernambuco. Recife, PE.

Alcock, J. (1997). Animal behavior: an evolutionary approach (3a ed.). Sunderland, Inglaterra: Sinauer Associates.

Alcock, J. (2011). Comportamento animal: uma abordagem evolutiva (9a ed.). Porto Alegre, RS: ARTMED.

Altmann, J. (1974). Observational study of behavior: sampling methodos. Behaviour, 49(3), 227-267.
Bertazzoni, E. C., Dall'acqua, P. E., Luiz, M. S. F., Vilas Boas, J. C. \& Albuquerque, L. B. (2005). Aspectos Comportamentais de Caracara Plancus (Falconidae) em duas áreas no pantanal da sub-região do Miranda/ Abobral, Corumbá (MS). In $16^{\circ}$ Congresso Brasileiro de Ornitologia (p. 73). Belém, PA.

Bezerra, M. de F. de A., Bezerra A. C. C., Nunes, A. T., Lado, C. \& Cavalcanti, L. de H. (2008). Mixobiota do Parque Nacional Serra de Itabaiana, SE, Brasil: Physarales. Acta Botânica Brasileira, 22(4), 1044-1056.

Birdlife International (2012). Caracara plancus. Disponível em IUCN Red List of Threatened Species. Version 2013.1. Recuperado de http://www.iucnredlist.org/ details/160032101/0

Broom, D. M. (1986). Indicators of poor welfare. British Veterinary Gournal, 142 (6), 524-526. Citado por Lima, C. dos S. et al. (2011). Bem estar e estresse animal em Harpias (Harpia harpyja) causado pelo ambiente criatório. In IV Simpósio de Ciências Agrárias de Pernambuco. Garanhuns, PE.

Carvalho, G. M. \& Vilar, J. G. (2005). Parque Nacional Serra de Itabaiana: levantamento da biota. Itabaiana: UFS-Universidade Federal de Sergipe.

Dove, C. J. \& Banks, R. C. (1999). A taxonomic study of crested caracaras (Falconidae). Wilson Bull, 111(3), 330-339.

Franzo, V. S., Artoni, S. M. B., Vulcani, V. S., Barreiro, F. R., Werther, K. \& Sagula, A. (2009). Considerações biométricas do sistema respiratório de carcará (Polyborus plancus). Ciência Rural, 39(1), 250-253.

Galetti, M. \& Guimarães Jr, P. R. (2004). Seed dispersal of Attalea phalerata (Palmae) by crested caracaras (Caracara plancus) in the Pantanal and a review of frugivory by raptors - Ararajuba. Revista Brasileira de Ornitologia, 12(2), 133-135.

Henrique, C. A. de M. \& Piratelli, A. (2008). Etograma de garça-branca-grande, Casmerodius albus (Ciconiiformes, Ardeidae). Revista Brasileira de Ornitologia, 16(3), 185-192.

Lima, C. S., Ludke, A. C. M. M., Neto, F. F. P., Pimentel, A. C. S. \& Valadares, C. G. (2011). Bem estar e estresse animal em harpias (Harpia harpyja) causado pelo ambiente criatório. In IV Simpósio De Ciências Agrárias de Pernambuco. Garanhuns, PE. 
Marini, M. A., Aguilar, T. M., Andrade, R. D., Leite, L. O., Anciâes, M., Carvalho, C. E. A., ... Gonçalves, J. (2007). Biologia da nidificação de aves do sudeste de Minas Gerais, Brasil. Revista Brasileira de Ornitologia, 15(3), 367-376.

Martinelli, M. M. (2010). Record of opportunist predation of Marine Catfish Genidens genidens Valenciennes, 1839 (Siliriformes, Ariidae) by the Crested-Caracara Caracara plancus Miller, 1777 (Falconiformes, Falconidae) in estuary of Jucu River, Espírito Santo, Brazil. PanAmerican Journal of Aquatic Sciences, 5(1), 162-165.

Mikich, S. B. (1991). Etograma de Ramphastos toco em cativeiro (Piciformes: Ramphastidae). Ararajuba, 2, 3-17.

Porto, G. R. P. \& Pitatelli, A. (2005). Etograma da mariapreta, Molothrus bonariensis (Gmelin) (Aves, Emberizidae, Icterinae). Revista Brasileira de Zoologia, 22(2), 306-312.

Prestes, N. P. (2000). Descrição e análise quantitativa do etograma de Amazona pretrei em cativeiro. Ararajuba, 8(1), 25-42.

Ribeiro, A. P., Vitalino, S. N., Escobar, A., Duque Ortiz, J. P., Belmore, E. A., Werther, K. \& Laus, J. L. (2008). Intraocular pressure and its correlation with blood gas parameters in crested caracaras (Caracara plancus) anesthetized with isoflurane and sevoflurane. Arquivos da Escola Veterinária da Universidade Federal de Minas Gerais, 60(6), 1461-1467.
Sazima, I. (2007). The jack-of-all-trades raptor: versatile foraging and wide trophic role of the Southern Caracara (Caracara plancus) in Brazil, with comments on feeding habits of the Caracarini. Revista Brasileira de Ornitologia, 15(4), 592-597.

Sick, H. (2001). Ornitologia brasileira. Rio de Janeiro, RJ: Nova Fronteira.

Souto, A. (2005). Etologia: princípios e reflexões (3a ed.). Recife, PE: UFPE.

Souto, N. H. (2008). Ecologia de interações entre Coragyps atratus (Bechstein, 1793) e Caracara plancus (Miller, 1777) no município de Uberlândia (MG). (Dissertação de mestrado). Universidade Federal de Uberlândia, Uberlândia (MG).

Tomazzoni, A. C., Pedó, E. \& Hartz, S. M. (2005). Feeding associations between capybaras Hydrochoerus hydrochaeris (Linnaeus) (Mammalia, Hydrochaeridae) and birds in the Lami Biological Reserve, Porto Alegre, Rio Grande do Sul, Brazil. Revista Brasileira de Zoologia, 22(3), 712-716.

Travaini, A., Donázar, J. A., Ceballos, O. \& Hiraldo, F. (2001). Food habits of the crested Caracara (Caracara plancus) in the Andean Patagonia: the role of breeding constraints. Fournal of Arid Environments, 48, 211-219. 